\title{
Challenges to ethical obligations and humanitarian principles in conflict settings: a systematic review
}

Grant Broussard', Leonard S. Rubenstein ${ }^{2,8}$, Courtland Robinson', Wasim Maziak, ${ }^{3,4}$ Sappho Z. Gilbert ${ }^{5}$ and Matthew DeCamp ${ }^{6,7^{*}}$ (D)

\begin{abstract}
Background: Humanitarian health care organizations and health workers working in contexts of armed or violent conflict experience challenges in fulfilling ethical obligations and humanitarian principles. To better understand the types of challenges experienced in these contexts, we conducted a systematic literature review.

Methods: A broad search strategy was developed for English language publications available in PubMed, Ovid/ EMBASE, and Scopus. The search relied upon three key concept blocks: conflict settings, humanitarian or relief organizations, and non-clinical or non-military ethics. To be included, publications had to (1) refer implicitly or explicitly to ethics and/or humanitarian principle(s), (2) relate to non-military relief work in active conflict or conflictaffected settings, (3) relate to organizational mission and/or delivery of services, and (4) relate to events after 1900. Records were qualitatively analyzed using an emergent thematic analysis approach that mapped challenges onto recognized ethical obligations and humanitarian principles.

Results: A total of 66 out of a possible 2077 retrieved records met inclusion criteria. The most frequently noted ethical challenges for organizations working in conflict settings were (1) providing the highest attainable quality of care, (2) protecting workers, and (3) minimizing unintended harms. The humanitarian principle most frequently noted as challenging to uphold was neutrality (the duty that humanitarian actors must not take sides in a conflict). Ethical challenges and humanitarian principles were commonly co-coded. For example, the challenge of providing the highest attainable quality of care frequently intersected with the humanitarian principle of humanity.

Conclusions: By categorizing the types of ethical challenges experienced by humanitarian care organizations, this review can help organizations anticipate issues that might arise in conflict settings. The identified relationships between ethical challenges and humanitarian principles suggests that frameworks and guidance for ethical decision-making, if adapted for conflict settings, could support organizational capacity to fulfill ethical and humanitarian commitments.
\end{abstract}

Keywords: Aid, Conflict, Ethics, Health, Humanitarianism, Violence

\footnotetext{
* Correspondence: matthew.decamp@cuanschutz.edu

${ }^{6}$ Berman Institute of Bioethics and Division of General Internal Medicine, Johns Hopkins University, Baltimore, USA

${ }^{7}$ Current affiliation: Center for Bioethics and Humanities and Division of General Internal Medicine, University of Colorado, Mailstop B137, 13080 E. 19th Avenue, Aurora, CO 80045, USA

Full list of author information is available at the end of the article
} 


\section{Introduction}

Humanitarian health organizations and health workers frequently work in conflict settings where they are subject to direct attack and where active armed conflict disrupts basic institutions and provision of services. Violence against humanitarian health workers, which may result in death, is a persistent and pervasive contemporary problem (Humanitarian Data Exchange (HDX) 2019; Safeguarding Health in Conflict Coalition (SHCC) 2018). Syria, in particular, has been called "the most dangerous place on earth for health-care providers" (Fouad et al. 2017).

Violent attacks against humanitarian health organizations and workers have many negative consequences. Health workers may suffer bodily injury, psychological harm, economic loss, and even death. Attacks can destroy hospitals and other facilities, disrupt delivery of essential supplies, interrupt service provision, and/or cause an organization to leave. Violent attacks can also discourage extending humanitarian assistance to where it is most needed.

Violent attacks not only violate international law (Rubenstein and Bittle 2010); they also create ethical challenges (Slim 2015). Health workers functioning in conflict settings may be faced with sudden and difficult decisions, including whether to practice outside their scope of training because of personnel shortages, how to deliver care when resources are limited or unreliable, which patients to treat when resource or security constraints prevent equal access, and how to maintain impartiality in providing care to both the victims and perpetrators of attacks, among many others. Humanitarian health care organizations face similarly challenging ethical issues, such as whether to rebuild destroyed facilities in more remote locations (which may negatively affect access), whether to focus special attention and resources in reaching vulnerable groups (when doing so might be detrimental to serving the most people possible), how much risk they can allow for their workers, and how to remain independent in the face of demands by combatants and donors.

Nevertheless, the full range of ethical and humanitarian challenges experienced by humanitarian health organizations-especially in conflict settings-has not been described. Understanding that range is essential for developing strategies to better manage them, but existing systematic reviews have not focused on ethical issues specifically (Chaudhri et al. 2019). In addition, whether existing frameworks for ethical decision-making in humanitarian action (Clarinval and Biller-Andorno 2014; Fraser et al. 2015) might apply or be useful in settings where health care workers and facilities are themselves subject to persistent attack remains unknown. To begin filling these knowledge gaps, we conducted a systematic literature review of the ethical and humanitarian challenges experienced by humanitarian health organizations in conflict settings. This systematic review is part of a larger project examining (via interviews and workshops) the organizational- and individual-level ethical challenges that humanitarian organizations have faced during the Syrian conflict.

\section{Methods}

\section{Search strategy}

Working with a research librarian, we developed a broad search strategy utilizing three core concept blocks: (1) conflict, (2) humanitarian or relief organizations, and (3) non-clinical or non-military ethics. We chose search terms for each concept block using controlled vocabulary and key terms with iterative search yield analyses. The first concept block included 13 search terms: "conflict," "war," "wars," "warfare," "revolution," "revolutions," "Arab spring," "uprising," "uprisings," "cruelty," "cruelties," or "high-risk environments." The second block consisted of seven search terms: "relief," "relief work," “aid," "humanitarian," "humanity," "NGO," or "NGOs." The third block included nine search terms: "ethics," "ethical," "morality," "professionalism," "professional duties," "neutrality," "principles," "independence," and "accountability." The full search strategy can be found in Additional file 1: Appendix 1.

\section{Screening process}

Three databases were searched: PubMed, Ovid/EMBASE, and Scopus. The searches returned 442 records in PubMed, 699 in Ovid/EMBASE, and 929 in Scopus. Titles and abstracts were independently screened by two study team members. To be included for full-text review, publications had to have an available full-text version, be published in English, and address all three key concept blocks. Publications that described only clinical ethics issues (e.g., truth telling or informed consent) that were not strictly related to a conflict setting were excluded; this ensured a consistent focus on those issues salient to, and arising in, conflict settings. Similarly, we excluded military ethics as not germane to humanitarian practice.

During full-text review, we applied the following inclusion criteria. To be included in qualitative analysis, a publication needed to (1) include reference, implicitly or explicitly, to ethics and/or humanitarian principle(s); (2) relate to non-military relief work in active conflict or conflict-affected settings; (3) relate to organizational mission and/or delivery of services; and (4) relate to events occurring in the twentieth century or later. To supplement the database searches, we also reviewed the reference lists of included publications. Disagreements about inclusion between the two initial reviewers were adjudicated by one or more additional study team member(s). 


\section{Data coding and abstraction}

Two study team members qualitatively analyzed the included articles using a thematic editing style (Campbell et al. 2011). Data were managed using NVivo software (QSR International Pty Ltd., Version 11.x, 2017).

First, a preliminary codebook was developed based on an informal review of the literature (Additional file 1: Appendix 2), the research team's experience and knowledge of the field, and consultation with experts in related areas of humanitarian ethics research, such as ethical issues that emerged in responding to the 20142015 Ebola epidemic. This preliminary codebook included two primary categories (i.e., "Ethical obligations" and "Humanitarian principles"). Within these categories, nodes were created to accommodate specific obligations and principles; within these nodes, subnodes were created to capture specific challenges to fulfilling the obligations and principles.

The "ethical obligations" category drew upon existing literature on ethical issues for humanitarian organizations and humanitarian health practice generally, in pandemics (e.g., influenza and Ebola [Kass et al. 2019]), in conducting research on sexual violence in emergency situations, and other areas (see Additional file 1: Appendix 2). Although ethical obligations of humanitarian health organizations and health workers may overlap, the focus of the codebook was the organizational level.

The "humanitarian principles" category drew upon the four widely accepted humanitarian principles: neutrality, impartiality, humanity, and independence (General Assembly resolution 46/182 1991; General Assembly resolution 58/114 2004; Pictet 1979; Sphere Project 2011). Neutrality is the duty that humanitarian actors must not take sides in a conflict. Impartiality stipulates that humanitarian actors must not discriminate or give preference to any nationality, race, religious belief, class, affiliation, or political opinion. Humanity means that human suffering must be addressed wherever and for whomever it is found. Independence demands that humanitarian actors retain their autonomy and remain independent of political or military objectives of other actors.

By employing these two main categories, we do not mean to imply that humanitarian principles and ethical obligations are fundamentally different in kind; at a high level, both are normative (i.e., they indicate what should or ought to be done). Our decision to differentiate them for analysis was motivated by three considerations. First, humanitarian principles and ethical obligations have different descriptive origins. Humanitarian principles originated more recently in operational, legal, and ethical frameworks for the Red Cross movement in its humanitarian activities; they have since been adopted by the United Nations and humanitarian organizations. Two of the principles, humanity and impartiality, provide what has been called "a moral ideal" for humanitarian action, while neutrality and independence are "practical tools for making humanity and impartiality a reality" (Labbé and Daudin 2016). Second, based on our initial literature review, the humanitarian and ethics literatures infrequently connect to each other; one goal of our review was to elucidate those connections in the peer-reviewed literature. Third, in practice humanitarian organizations and workers may view and use humanitarian principles and ethical obligations differently; this assumption was later borne out in workshops we conducted as part of the larger project. In these workshops, for example, attendees viewed humanitarian principles more as motivating ideals, whereas ethical obligations were viewed as more specifically action-guiding.

Second, the preliminary codebook was used by two study team members to review ten randomly selected full-text articles. After independently reviewing the articles, the study team members met to discuss and resolve category coding differences. At this stage, two major additions were made to the codebook. In the "ethical obligations" category, the obligation of appropriate acquisition and management of assets (including financial, material, and human assets) was added as a node (Civaner et al. 2017; Hunt 2008). In the "humanitarian principles" category, the principle of "solidarity" was added as a node, as it was noted to be an emerging humanitarian principle. In the literature, solidarity has been defined in different ways to include concepts of political advocacy, human rights, shared suffering, and consultation with those affected (Hunt et al. 2014; Hurst et al. 2009; Omaar and de Waal 1994; Slim 1997a, b). In light of solidarity being a more recently emergent principle lacking a single standard definition in the literature, for the purposes of coding, we employed a broad conception of solidarity that encompassed all of these possible uses.

Third, the two study team members used the revised codebook to re-code the same ten articles, and results were compared. The comparison revealed differences related to length of text coded and frequency of coding, but not the presence or absence of nodes. Satisfied with the reliability of coding, the two study team members proceeded to independently code the remaining articles. Text passages were coded line-by-line using this scheme. Passages that were difficult to interpret were discussed and coding was reconciled through discussion among the entire study team.

The two primary categories were not mutually exclusive. Given the nature of our subject matter-ethics and humanitarian principles in conflict settings-and our goal to describe and categorize the range of issues arising, we did not assess the "quality" of included articles overall or of any specific statements or arguments presented. 


\section{Results}

This search yielded 2077 records. After 451 duplicates were removed, and 1537 records were excluded during abstract and title review, 89 articles were selected for full-text review. Of these, 23 did not meet inclusion criteria. Reference list review yielded an additional seven publications. In total, 66 articles met inclusion criteria and were included in the analysis (see Fig. 1 for the study flow diagram and Additional file 1: Appendix 3 for the list of 66 included articles).

A full summary table of qualitative findings with representative quotations can be found in Additional file 1: Appendix 4. Below, we present key summary findings. In reporting numbers, " $\mathrm{N}$ " refers to the total number of articles with the code applied, and " $n$ " refers to the number of individual coding instances (i.e., a single article could include multiple coding instances).

\section{Ethical obligations}

Table 1 presents findings related to ethical obligations. The organizational ethical obligation most frequently coded was providing the highest attainable quality of care and services. This obligation was discussed in 52/66 (79\%) of sources and was also the most frequently assigned code. Challenges to fulfilling this obligation included disruption in available supplies and services, difficulty getting supplies and services to the front lines (even when they were available), and a perceived lack of accountability for quality of care (e.g., documented impact, quality reporting, and so on).

Appropriate acquisition and management of assets (i.e., informational, financial, and human assets) was an ethical obligation that emerged in the analysis. This obligation operated at the organizational management level (e.g., when an organization faces difficulties in maintaining a stable workforce).

The third most frequently coded obligation related to protecting and caring for workers (i.e., the "duty to care" in the humanitarian literature). The duty to care can be a legal obligation that employers must meet regarding their employees. In humanitarian settings and more broadly from the standpoint of ethics, it more commonly refers to the recognized ethical obligation of organizations to foresee, prepare for, and mitigate the impacts of working in a complex, stressful, and sometimes dangerous environment. A particular challenge related to this obligation was concern over "risk transfers," or situations where organizations might seek to mitigate their own

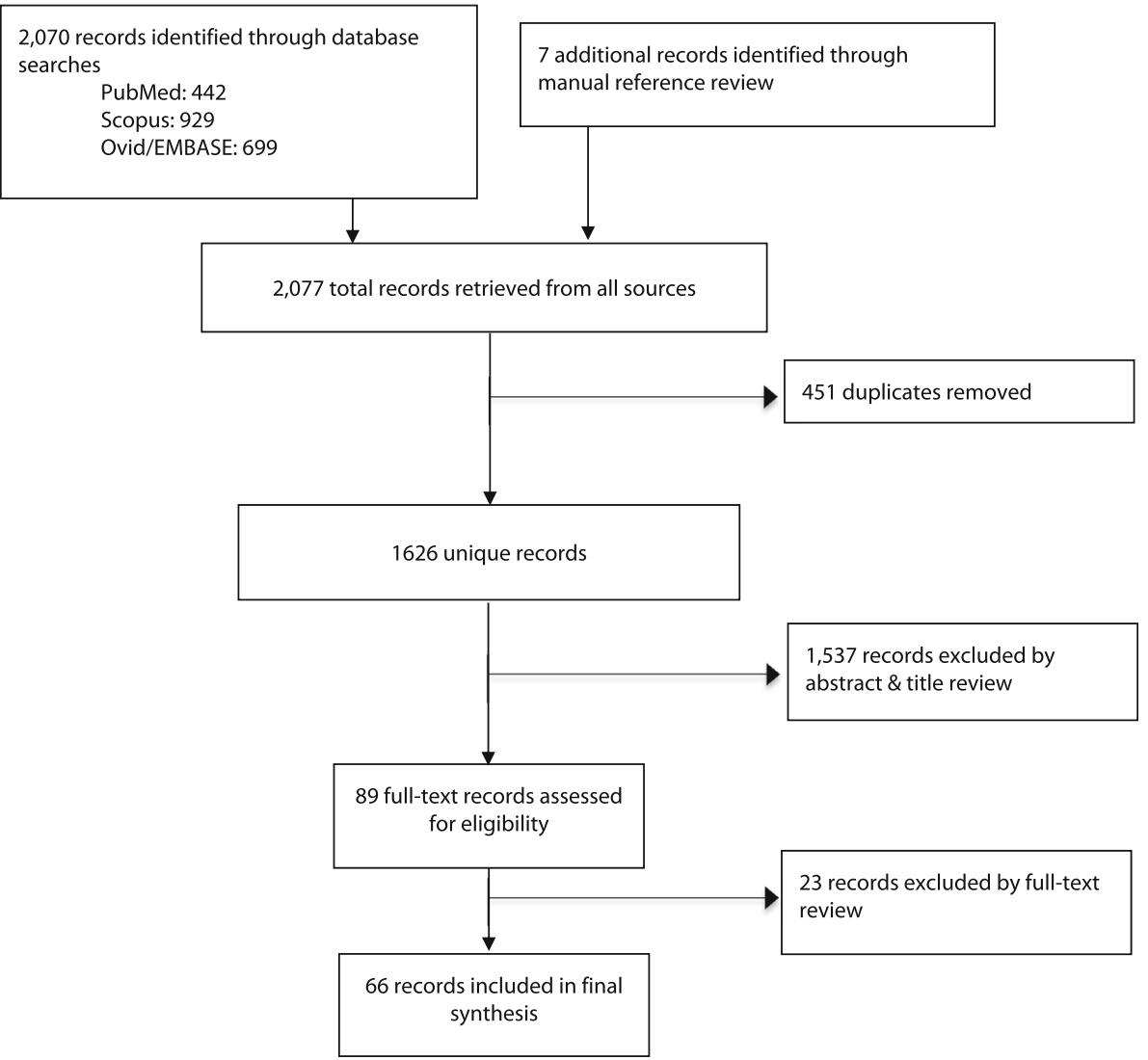

Fig. 1 Search flow diagram 
Table 1 Coding frequencies of ethical obligations, including the top coded challenges

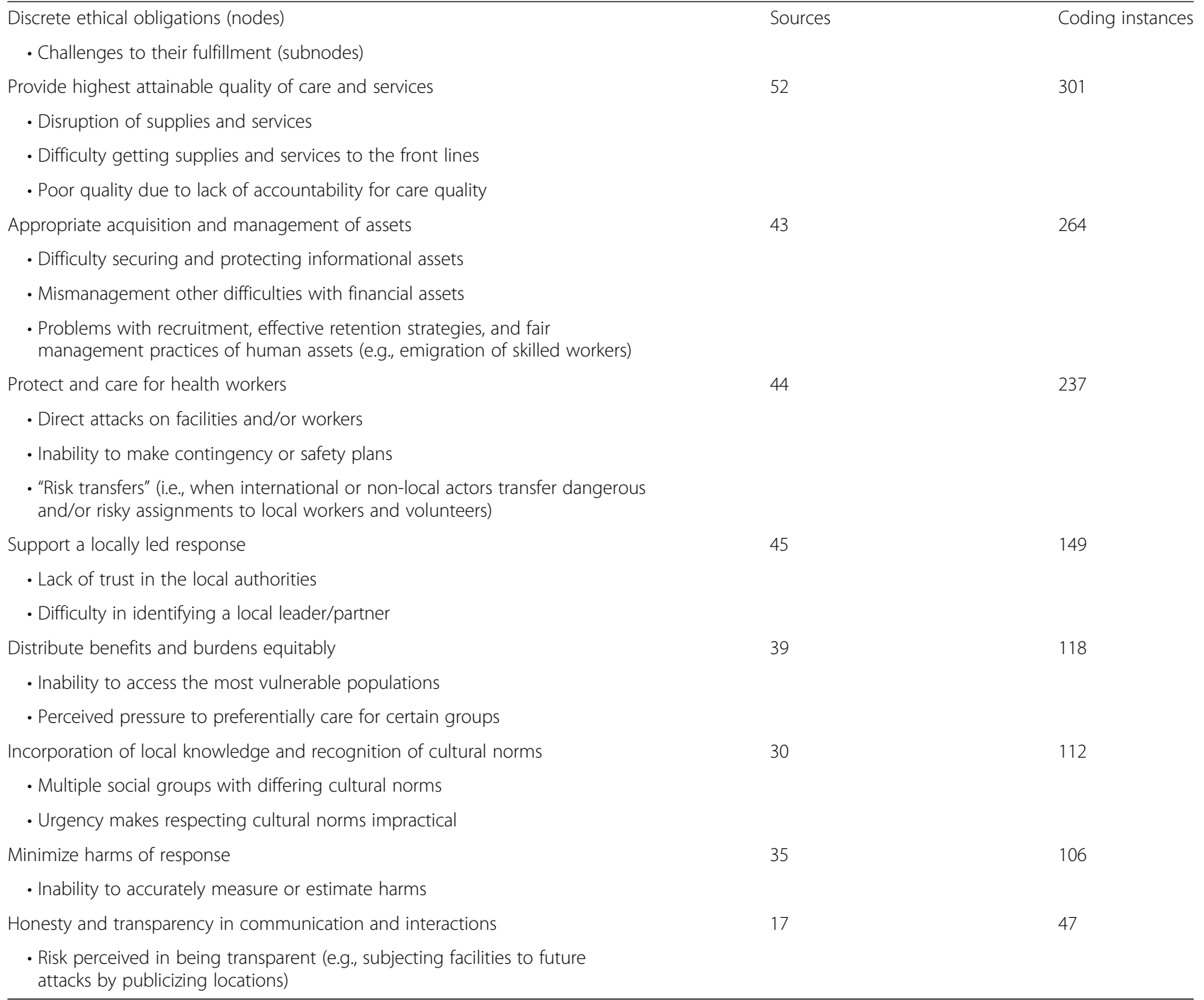

risks or risks to their workers by transferring them to others (e.g., by assigning certain tasks to local individuals).

\section{Humanitarian principles}

Table 2 summarizes findings related to humanitarian principles evident in the literature reviewed. Neutrality was coded most frequently. A significant challenge to neutrality was the idea that aid itself could be perceived as political. For example, when an aid organization works closely with a local population, that association could be perceived as compromising neutrality if the local population is perceived to be on one side of the conflict.

Challenges to the principle of independence were also prevalent. For example, organizations' commitments to independence could come into question due to political or financial ties with state agencies, non-state groups, or donors that might restrict an organization's activities, even if these ties were merely perceived. Nontransparency related to budgetary or programmatic decision-making was another commonly coded situation where independence could be in question.

Regarding impartiality, pressure on organizations to show favoritism to one group over another was the most frequent subnode. For example, some sources described situations where organizations were forced to choose between losing access to an entire population or yielding to demands of armed groups to give preferential treatment to their members. Even without this type of overt pressure, humanitarian health organizations could sometimes be compelled to concentrate aid work in safe or more easily accessible areas.

The intersection of ethics and humanitarian principles As described in our methods, coding of humanitarian principles and ethical obligations was not mutually 
Table 2 Coding frequencies of humanitarian principles, including the top coded challenges

\begin{tabular}{|c|c|c|}
\hline Individual humanitarian principles (nodes) & Sources & Coding instances \\
\hline \multicolumn{3}{|l|}{ - Challenges to their fulfillment (subnodes) } \\
\hline Neutrality & 48 & 283 \\
\hline \multicolumn{3}{|l|}{ - Aid can itself be perceived as political } \\
\hline \multicolumn{3}{|c|}{ - Tension between witnessing and reporting violence and remaining neutral } \\
\hline Independence & 44 & 205 \\
\hline \multicolumn{3}{|c|}{ - Funding sources and connections perceived as compromising independence } \\
\hline \multicolumn{3}{|c|}{$\begin{array}{l}\text { - Organizations implicated in conflicts due to their having resources } \\
\text { and investments surrounding the conflict }\end{array}$} \\
\hline Humanity & 44 & 153 \\
\hline \multicolumn{3}{|c|}{ - Inability to reach those known to be in need } \\
\hline Impartiality & 40 & 133 \\
\hline \multicolumn{3}{|c|}{ - Pressures on organization to provide assistance not based solely on greatest need } \\
\hline Solidarity & 21 & 29 \\
\hline $\begin{array}{l}\text { - Challenges to promoting solidarity, inclu } \\
\text { or "us"/"them" attitude, among others }\end{array}$ & & \\
\hline
\end{tabular}

exclusive. Table 3 displays the frequency of co-coding these two categories; Table 4 illustrates this intersection with five examples.

In some instances, this intersection was found to represent apparent tension between fulfilling humanitarian principles and ethical obligations. For example, the ethical obligation to support a locally-led response could be in tension with the humanitarian principle of independence when local community members are aligned with one side of the conflict or another. Similarly, the ethical obligation to provide honest and transparent communication could be in tension with the principle of independence, for example, if distributing communication relies upon state-owned media. In other instances, this intersection was found to be mutually supportive. For example, the ethical obligation of ensuring a fair distribution of the benefits and burdens of aid supports fulfilling the humanitarian principle of impartiality. We explore the relationship between ethical obligations and humanitarian principles further in the "Discussion" section.

\section{Management strategies}

While not the focus of our review, coders did make note of strategies organizations used to attempt to manage identified challenges. Without endorsing these as the best or only correct strategies, these are listed in Additional file 1: Appendix 4. We highlight several here.

Some organizations have responded to the obligation to protect workers, for example, by creating secure operational sites with minimal and/or strictly controlled access to the outside world (a strategy known as "bunkerization"). Such a strategy can protect workers, but may occur at the expense of another obligation, i.e., involving locals in operational planning and management. By contrast, for example, some organizations have created formal decision-making processes inclusive of all stakeholders, including aid recipients, for the sake of transparency and to facilitate incorporation of local knowledge and norms. Regarding humanitarian principles, for instance, some organizations have maintained independence by refusing to accept funds conditional upon particular program changes or by investing and

Table 3 Intersections between ethical obligations and humanitarian principles

\begin{tabular}{|c|c|c|c|c|c|c|c|c|}
\hline & $\begin{array}{l}\text { Provide highest } \\
\text { attainable quality of } \\
\text { care and services }\end{array}$ & $\begin{array}{l}\text { Protect and } \\
\text { care for } \\
\text { response } \\
\text { workers }\end{array}$ & $\begin{array}{l}\text { Minimize } \\
\text { harms of } \\
\text { response }\end{array}$ & $\begin{array}{l}\text { Support a } \\
\text { locally led } \\
\text { response }\end{array}$ & $\begin{array}{l}\text { Appropriate } \\
\text { acquisition and } \\
\text { management of } \\
\text { assets }\end{array}$ & $\begin{array}{l}\text { Distribute } \\
\text { benefits and } \\
\text { burdens } \\
\text { equitably }\end{array}$ & $\begin{array}{l}\text { Practice } \\
\text { honesty and } \\
\text { transparency }\end{array}$ & $\begin{array}{l}\text { Incorporate } \\
\text { local } \\
\text { knowledge } \\
\text { and norms }\end{array}$ \\
\hline Neutrality & $n=40$ & $n=26$ & $n=24$ & $n=19$ & $n=10$ & $n=31$ & $n=10$ & $n=15$ \\
\hline Independence & $n=43$ & $n=18$ & $n=23$ & $n=21$ & $n=29$ & $n=24$ & $n=10$ & $n=13$ \\
\hline Impartiality & $n=25$ & $n=9$ & $n=14$ & $n=13$ & $n=9$ & $n=38$ & $n=4$ & $n=12$ \\
\hline Humanity & $n=73$ & $n=17$ & $n=19$ & $n=16$ & $n=28$ & $n=39$ & $n=6$ & $n=8$ \\
\hline Solidarity & $n=4$ & $n=3$ & $n=3$ & $n=3$ & $n=4$ & $n=3$ & $n=1$ & $n=1$ \\
\hline
\end{tabular}


Table 4 Examples that illustrate the potential intersection between humanitarian principles and ethical obligations

\begin{tabular}{lll}
\hline Intersection & Example description & Example quotation Emphasis added \\
\hline $\begin{array}{ll}\text { Neutrality and highest attainable } \\
\text { quality of care }\end{array}$ & $\begin{array}{l}\text { Delivering high-quality care may not be viewed as } \\
\text { "neutral" in a conflict when delivering that care comes } \\
\text { under the authority of one side or the other. }\end{array}$ & $\begin{array}{l}\text { Once the international community's resolve to enforce } \\
\text { international law was revealed as a sham, Hutu- } \\
\text { supremacist camp authorities were able to close down } \\
\text { humanitarian space to a point where agencies were } \\
\text { faced with a stark choice: either provide assistance to } \\
\text { refugees under terms set by the camp authorities or get }\end{array}$ \\
$\begin{array}{ll}\text { out. Most agencies chose the former, while continuing } \\
\text { to call for "political action." Finding accommodation }\end{array}$ & $\begin{array}{l}\text { with camp authorities involved accepting some } \\
\text { diversion of relief goods through the taxation of } \\
\text { beneficiaries by their political masters. (Fennell 1998) }\end{array}$
\end{tabular}

Humanity and highest attainable The goal of relieving the suffering of all in settings of quality of care

Independence and supporting a locally led response

Impartiality and equity

Independence and honesty and transparency extreme violence may mean the highest quality of care cannot be met.

When local groups are on one side or the other of a conflict, an organization supporting a locally led response could be perceived as no longer fully independent.

Providing aid to all victims impartially supports the obligation of an equitable distribution of the benefits and burdens of aid.

Being honest and transparent about, for example, witnessed atrocities could be perceived as compromising independence.
The participants report concern of medical competence as a potential source of ethical problems. They state that in general [health care workers] sent to disaster settings are not properly trained specifically for disasters... Some of them state that lack of proper education makes it difficult to be benevolent to victims. (Civaner et al. 2017)

Armed actors-both state and non-state-will frequently seek to associate themselves with aid efforts to enhance their legitimacy in the eyes of affected people. Agencies cited examples of this in all four settings [i.e., Afghanistan, South Central Somalia, South Sudan and Syria]. One agency representative working in Damascus said that questions about whether the government could be taking credit or profiting from the aid effort "keep [them] up at night." Non-state armed groups such as IS and Al-Shabaab sought to associate themselves positively with aid projects, for instance by turning up at distributions or, in the case of IS, making a propaganda film about a health clinic. (Haver 2016)

Access can diminish both as a direct result of violence and as a consequence of the obstacles and conditions created by militaries, governments, and non-state actors that hinder the impartial provision of aid. In an effort to maintain their presence and continue to deliver on their humanitarian commitments, a number of humanitarian organisations have strengthened their risk management capabilities... increasing their access to affected populations. (Egeland et al. 2011)

Humanitarian aid workers from Médecins Sans Frontières (MSF, Doctors Without Borders) were present in the town before and during its fall. For months before the genocide, certain headquarters staff members believed the situation of the "safe area" was untenable, but the organization refrained from conducting advocacy in light of the tenuous presence the aid workers had in the town... In contrast, over the roughly two weeks that the town was falling and its inhabitants were targeted and terrorized, the organization did go to the media with testimony from its two international staff members. (Fink 2007) developing their own asset management strategies to avoid reliance upon, or sharing assets with, partisan groups. Such an approach maintains both real and perceived independence.

\section{Discussion}

This systematic review yielded three principal findings related to ethical and humanitarian challenges experienced by humanitarian health organizations in conflict settings. First, the relative frequencies of the ethical obligations and humanitarian principles described provide insight into the types of issues organizations are likely to encounter. Second, our findings have identified common ways in which ethical obligations and humanitarian principles can be mutually challenged in conflict settings. Third, by identifying points of overlap between ethical obligations and humanitarian principles, this review could motivate exploration of innovative approaches to 
meeting these challenges (e.g., by exploring whether management of ethical challenges could help organizations better fulfill humanitarian principles).

\section{Ethical obligations and challenges}

In our review, the most commonly identified challenges to providing the highest attainable quality of care and services involved logistical obstacles such as disruptions or shortages of food or medical supplies, personnel, or care services and difficulties getting medicine and providers to front lines to meet communities' needs. Challenges to this obligation, founded on the ethical principle of beneficence, include disparities in the availability of facilities and supplies in conflict settings as compared to that of many workers' home contexts (Baskett 1994; Bernthal et al. 2014; Civaner et al. 2017; Hunt 2008; Hunt et al. 2014), the existence of counterfeit or low-quality supplies and medications (Burkle Jr. et al. 2017; Michael and Zwi 2002), and policies restricting the administration of care to select populations and blocking access to certain locations (Al-Moujahed et al. 2017; Civaner et al. 2017; Clarinval and Biller-Andorno 2014; Fouad et al. 2017).

Our findings also highlight an additional dimension to the duty to provide high-quality care: accountability. Fulfilling the obligation to provide high-quality care requires explicit evaluation of outcomes, without which the quality cannot be assured (Al-Moujahed et al. 2017; Burkle Jr. et al. 2017; Civaner et al. 2017; Clarinval and Biller-Andorno 2014; Fouad et al. 2017).

Even when organizations attempt, at a minimum to meet their duties of beneficence by avoiding causing harm, they could face challenges in doing so. Organizations may fear that providing aid could unintentionally sustain conflicts (Banatvala and Zwi 2000; Black 2003; Clarinval and Biller-Andorno 2014; Duffield et al. 2012; Fink 2007; Gardemann 2002; Hunt 2008; Michael and Zwi 2002; Poffley 2012; Slim 1997a, b). Moreover, there were concerns that humanitarian aid could destabilize established in-country health and other support systems and create unsustainable programs that result in support gaps when aid programs depart (Hunt 2009; Jaspars and O'Callaghan 2010; Rieffer-Flanagan 2009). Lack of training for workers (especially in disaster- or conflictspecific competencies) was cited as leading to inadequate or inappropriate care for vulnerable populations and forcing workers to make ad hoc decisions about triage and prioritization of patients and treatments-resulting in suboptimal care (Civaner et al. 2017; Fouad et al. 2017; Joshi et al. 2008).

Challenges related to the appropriate acquisition and management of assets arose from informational and financial factors. For instance, a lack of interorganizational information sharing (Haver 2016) or an inability to attain necessary information due to operational restrictions (Bernthal et al. 2014) could make it more difficult to manage material and personnel resources when delivering aid. Financially, for example, external constraints related to the need to maintain relationships with existing and future donors (Cobey et al. 1993; Gastineau Campos and Farmer 2003; Haver 2016; MacCormack 2007; Weiss 2016) and internal constraints related to the need to sustain existing programs and staff (Michael and Zwi 2002) could affect organizations' abilities to adjust resource management nimbly in response to ever-changing circumstances (Clarinval and Biller-Andorno 2014; Hurst et al. 2009; Leaning et al. 2011). The inability to recruit and retain skilled individuals can require organizations to fill essential staffing gaps with unqualified or untrained individuals (Fouad et al. 2017) - an action that could present a challenge to the provision of high-quality care.

Quality of care and resource management intersected the ability of organizations to realize an equitable distribution of benefits and burdens, an obligation of justice or fairness, and minimizing harms of a response. For organizations operating amidst resource shortages, in settings where local health systems have been destroyed, or with other critical limitations (Al-Moujahed et al. 2017; Gardemann 2002; Haver 2016), it is nearly impossible to treat all potential beneficiaries equitably or reach those most in need. Extremely dangerous security situations can result in providing aid preferentially to those in safer areas when, ideally, aid should be provided equitably to all and provided based on need (Clarinval and Biller-Andorno 2014; Egeland et al. 2011; Haver 2016; Leaning et al. 2011; Poffley 2012).

Organizations may also need to be aware of other sources of differential care that raise ethical concerns. These can include the personal prerogatives of humanitarian workers themselves (Ben Shahar 1993; Civaner et al. 2017), gaps in situational awareness that allow dishonest actors to present distorted views of needs (Fegley 2009; Gardemann 2002; Haver 2016; Hunt et al. 2014), and threats of violence or criminal prosecution against health workers (Blair 1996; Fouad et al. 2017; Haver 2016).

Protecting and caring for health workers (i.e., the "duty to care") is another recognized obligation of humanitarian organizations. Advancements in operational security (Egeland et al. 2011) and a growing acceptance of increased danger in humanitarian endeavors (Duffield et al. 2012) may expand the breadth of humanitarian efforts in conflict settings, making this obligation ever more central. There is a growing appreciation of the organizational responsibility to protect its workers and acknowledgement of the diminished ability to provide quality care due to security concerns when organizations operate within conflict settings (Asgary 2015; Banatvala 
and Zwi 2000; Fouad et al. 2017). There is also a recognized need to ensure that health workers are adequately informed about these risks. To be sure, the obligation to protect workers is not the humanitarian organization's alone; the international community, via international humanitarian law, also plays a role in protecting humanitarian health workers (Burkle Jr. et al. 2017; Fennell 1998; Fouad et al. 2017; O'Callaghan and Leach 2014).

Our review identified a specific ethical concern regarding one way organizations might protect their own workers: "risk transfers." Risk transfers, which occur when international or non-local actors transfer dangerous assignments to individuals outside their organization, usually to local actors (thereby meeting another ethical obligation regarding involving local communities), could meet the organization's obligation to protect its own workers at the expense of others' safety (Egeland et al. 2011). Yet the ethical appropriateness of this practice has been to date underexplored.

Supporting a locally-led response is an obligation based on the idea of fair decision-making processes. The collapse of in-country health systems (Al-Moujahed et al. 2017; de Waal 2010; Michael and Zwi 2002); difficulty in identifying and trusting local leaders (Black 2003; Cobey et al. 1993; Fouad et al. 2017; Haver 2016; Weiss 2016); and tensions arising between organizational, individual, and local beliefs and norms (Civaner et al. 2017; Egeland et al. 2011; Fegley 2009; Fraser et al. 2015) all make fulfilling this obligation challenging.

Practicing honesty and transparency in communications was an important theme in our review. A notable challenge to honest communication was the perception that open communications could subject organizational assets to additional risks (e.g., by subjecting them to further attacks) (Redwood-Campbell et al. 2014).

\section{Relationships among ethical obligations and challenges} Although the relationship between different ethical obligations was not typically explicit in the literature, we noted how ethical obligations could be either in tension or mutually supportive.

Regarding tensions, for example, the duty to provide the highest quality care (which could require significant resources) could be in tension with the duty to humanity, i.e., to relieve suffering wherever it was found (which could require devoting fewer resources but to more individuals in need). It is also possible that meeting some obligations, such as those regarding open communications, locally-led responses, and respecting cultural norms, could require dedicated resources and deliberate planning that might detract from efforts to provide aid to all in a timely manner (a tension experienced even if this short-term loss is made up with longer-term benefits regarding sustainability).
Ethical obligations can be mutually supportive, however. A commitment to engaging local communities in planning and aid efforts, for example, helps identify and minimize potential harms and unintended consequences as well as promoting respect for cultural norms (Egeland et al. 2011; Haver 2016; Hurst et al. 2009; Jaspars and O'Callaghan 2010; Tribe et al. 2014). Appropriate resource management strategies make it more likely that organizations can meet their obligations to deliver the highest possible quality of care (Banatvala and Zwi 2000; Blair 1996; Leaning et al. 2011).

The precise ways in which ethical obligations are in tension or are mutually supportive are context dependent. Identifying and mapping these relationships could help organizations manage ethical issues arising during operations.

\section{Humanitarian principles and challenges}

Our review identified that the primary challenges to neutrality were perceptions that humanitarian assistance was innately political (Fouad et al. 2017; Geiger et al. 1989; Madhiwalla and Roy 2009) and that the very act of working in conflict settings implied some type of political affiliation (Rieffer-Flanagan 2009). Military and political interventions operating under the guise of humanitarian aid can lead combatants or beneficiaries to doubt the neutrality of humanitarian organizations (Asgary 2015; Clarinval and Biller-Andorno 2014; Cobey et al. 1993; Duffield et al. 2012; Egeland et al. 2011; Gastineau Campos and Farmer 2003). Perceptions of non-neutrality can arise from using military escorts for protection (Egeland et al. 2011; MacCormack 2007; Poffley 2012; Slim 1995), the non-neutral conduct of partners (Egeland et al. 2011; Haver 2016), or if combatants insert themselves between humanitarian actors and aid beneficiaries (Fegley 2009).

Maintaining neutrality can also be difficult for organizations whose workers have experienced violence, threats, or compulsion, or have borne witness to violence or advocated on behalf of victims of atrocities (Blair 1996; Burkle Jr. et al. 2017; Civaner et al. 2017; Farré 2013; Geiger et al. 1989; Slim 1997b). Organizational members' own personal political views could also affect perceptions of organizational neutrality (Jones 2009). Humanitarian organizations operating in resource scarce settings can also be perceived as lacking neutrality because of how they allocate resources and maintain secure access to those in need. Organizations can inadvertently or unwittingly become affiliated with other political objectives, for example, if they capitalize upon access gained by other, partisan groups, or use security services (e.g., formal military support) (Black 2003; Clarinval and Biller-Andorno 2014; Egeland et al. 2011; Gastineau Campos and Farmer 2003; Haver 2016; 
Mačák 2014; Slim 1995; Sunga et al. 2006; Weiss 2016). Additionally, working with local populations could be seen as a tacit endorsement of an ideology or political view (Joshi et al. 2008).

Organizational independence can be challenging to uphold. In complex emergencies with significant societal breakdowns, unscrupulous actors may take advantage of humanitarian organizations, restricting organizational activities in ways that advance their own agendas (Burkle Jr. et al. 2017; de Waal 2010). Unfortunately, when this occurs, it can also create a proximity effect that casts doubt upon the independence of other humanitarian organizations (Civaner et al. 2017; Rieffer-Flanagan 2009; Slim 1995). Funding sources can compromise independence by taking decision-making authority away from organizations if funding is conditional, e.g., specifying services offered or populations served (Clarinval and Biller-Andorno 2014; Harding-Pink 2004; MacCormack 2007; Slim 1997b).

A key threat to impartiality arose from external pressures to provide assistance not purely in accordance with need. These pressures could include extortionary negotiations demanding preferential treatment to gain access for combatants (Fennell 1998) and criminalization of providing aid to certain groups (Fouad et al. 2017). When threats to impartiality result in aid given to combatants (e.g., when threats of violence force health care workers to provide aid to combatants to prevent worse harm to others), organizations and workers may believe they are complicit in prolonging conflict (Fink 2007) and/or have violated their duty to be impartial (Geiger et al. 1989; Madhiwalla and Roy 2009). This can also result in restricting programs to more secure areas regardless of the needs of people living in insecure areas (Haver 2016).

Societal breakdowns, the loss of normal order, and punitive actions against humanitarian organizations severely limit their ability to fulfill their duty of humanity (Al-Moujahed et al. 2017; Fouad et al. 2017; Haver 2016; Poffley 2012). Violent threats, abduction, torture, and murder of humanitarian workers; blockade and theft of materials and supplies; and the elimination of access to or destruction of facilities also drastically impede humanitarian missions (Alderslade 1995; Blair 1996; Cobey et al. 1993; Fennell 1998; Fouad et al. 2017; Geiger et al. 1989; Haver 2016; Madhiwalla and Roy 2009; RedwoodCampbell et al. 2014). Efforts to avoid violence, such as concentrating operations in safe or comparatively secure areas, preclude access or attention to the most vulnerable and in need (Haver 2016). Facilities in conflict regions are often operating beyond their capacity and providers are unable to meet demands in high-volume crises or complex medical cases (Baskett 1994; Ben Shahar 1993; Domres et al. 2012; Leaning et al. 2011).
Additionally, material scarcity and personnel shortages contribute to organizations' limited efficacy of meeting the needs of beneficiaries (Hunt 2008).

Threats to the emergent humanitarian principle of solidarity were experienced in several ways. For example, because solidarity implies both suffering with and consulting community members, lack of coordination between organizations could lead to disorder, duplicative efforts, or blind spots in identifying community needs. This in turn can undermine organizations' capacity for solidarity (MacCormack 2007). In addition, humanitarian workers themselves may struggle to feel they are in solidarity with local populations. Barriers to recognizing solidarity can also be exacerbated in violent situations and other complex emergencies where extreme circumstances can increase and reinforce humanitarian workers' perceptions of "otherness" (e.g., because of cultural and language differences and/or economic disparities) of populations being served (Hunt et al. 2014).

\section{Implications of the relationship between ethical obligations and humanitarian principles}

Our review found multiple instances where ethical obligations and humanitarian principles intersect (Tables 3 and 4). The implications of this intersection are twofold. First, observing this connection brings additional clarity to the nature of the challenges humanitarian organizations may face when operating in conflict settings. For instance, seen through the intersection of ethics and humanitarian principles, the obligation to involve local communities in humanitarian response relates to fundamental ethical obligations of justice that involve fairness in decision-making, may help facilitate respect for local community norms, and could improve an organizations' ability to deliver aid to communities in need, thereby meeting humanitarian obligations of humanity. At the same time, this must be done carefully, to preserve the humanitarian commitment to independence.

Second, the intersection between ethics and humanitarianism in conflict settings creates the potential for using ethical decision-making to support and improve humanitarian action. Workshops were conducted with Syrian humanitarian health workers in Gaziantep, Turkey and Amman, Jordan to review an earlier version of our literature review findings. Attendees supported both our original decision to categorize humanitarian principles and ethical obligations separately and the potential for having a better understanding of their intersection to improve organizational decision-making around ethical challenges. Frameworks for ethical decision-making have been proposed for humanitarian settings (Clarinval and Biller-Andorno 2014; Hunt 2008). These frameworks share a commitment to creating decision processes that help identify the ethical issues at 
stake in a particular situation and make better decisions around them. However, the ethical issues at stake may not always be clear to organizational stakeholders. Having investigated ethics obligations, humanitarian principles, and their inter-relationships, our review should help organizations better operationalize existing frameworks as they strive to maintain their ethical and humanitarian commitments and make better decisions. Still, we must acknowledge that whether these frameworks are both applicable and feasible in conflict settings remains an open question and should be the subject of future research.

\section{Limitations}

First, the search included only English language publications. Second, it is possible that not all the ethical and humanitarian challenges organizations experience are reported in the published literature. Third, our review did not include gray literature such as reports from think tanks, humanitarian organizations, and $\mathrm{UN}$ agencies, raising the possibility the other obligations and challenges have been identified. Fourth, we did not assess the quality of included publications. Finally, as a qualitative study, our findings involve subjectivity. It is possible that a different research team would produce different findings or come to different conclusions from these data. We believe that a broad initial search strategy and a structured method of qualitative content analysis helped address these limitations.

\section{Conclusion}

Conflict settings present substantial barriers to humanitarian health response efforts. By describing the range of challenges humanitarian organizations have faced in fulfilling their basic ethical obligations and humanitarian principles, this review can increase awareness of the nature and types of challenges organizations are likely to experience while trying to uphold their commitments in conflict settings. This can in turn aid organizational preparedness, including stimulating efforts to train and monitor humanitarian health workers and develop processes for addressing challenges in the field. In addition, it lays the foundation for future efforts aimed at tailoring existing frameworks for ethical decision-making and evaluating different methods of navigating these complex challenges.

\section{Additional file}

Additional file 1: Appendix 1. Full searches as executed in each of the three databases (Ovid/EMBASE, Scopus, and PubMed) on May 17, 2017 (at 1:00, 1:08, and 1:15 PM EST, respectively). Appendix 2. References used for codebook development. Appendix 3. Articles included in the review $(\mathrm{N}=66)$. Appendix 4. Summary of main findings by organizational ethics and humanitarian principle ( $\mathrm{N}=$ number of articles where this code was applied, and $n=$ numbers of references where it was coded across the $\mathrm{N}$ articles). (DOCX $54 \mathrm{~kb}$ )

\section{Acknowledgements}

The authors are grateful to Rachel Fabi, PhD, for earlier contributions to the study.

\section{Authors' contributions}

GB made substantial contributions to the acquisition, analysis, and interpretation of the data and the drafting of the manuscript. LR made substantial contributions to the conception and design of the study; the analysis and interpretation of the data; and revised the manuscript critically for important intellectual content. CR made substantial contributions to the conception and design of the study; the analysis and interpretation of the data; and revised the manuscript critically for important intellectual content. WM made substantial contributions to the interpretation of the data and revised the manuscript critically for important intellectual content. SG made substantial contributions to the acquisition of the data and revising the work critically for important intellectual content. MD made substantial contributions to the conception and design of the study; the analysis and interpretation of the data; and the drafting of the manuscript. All authors agree to be accountable for the accuracy and integrity of the work and gave final approval of the manuscript.

\section{Authors' information}

The authors choose not to provide this information.

\section{Funding}

This research was funded by Elrha's Research for Health in Humanitarian Crises (R2HC) programme, funded equally by the Wellcome Trust and DFID, with Elrha overseeing the programme's execution and management. Its contents are solely the responsibility of the authors and do not necessarily represent the official views of Elrha or the $\mathrm{r} 2 \mathrm{hc}$. This funding source had no role in the design of this study, the analysis or interpretation of data and results, or the decision to write and submit the manuscript.

\section{Availability of data and materials}

The datasets used and/or analysed during the current study are available from the corresponding author on reasonable request.

\section{Competing interests}

The authors declare that they have no competing interests.

\section{Author details}

'Department of International Health, Johns Hopkins Bloomberg School of Public Health, Baltimore, USA. ${ }^{2}$ Center for Public Health and Human Rights, Johns Hopkins Bloomberg School of Public Health, Baltimore, USA.

${ }^{3}$ Department of Epidemiology, Florida International University, Miami, USA. ${ }^{4}$ Syrian American Medical Society, Washington DC, USA. ${ }^{5}$ Department of Chronic Disease Epidemiology, Yale School of Public Health, New Haven, USA. ${ }^{6}$ Berman Institute of Bioethics and Division of General Internal Medicine, Johns Hopkins University, Baltimore, USA. ${ }^{7}$ Current affiliation: Center for Bioethics and Humanities and Division of General Internal Medicine, University of Colorado, Mailstop B137, 13080 E. 19th Avenue, Aurora, CO 80045, USA. ${ }^{8}$ Berman Institute of Bioethics, Johns Hopkins University, Baltimore, USA.

Received: 22 April 2019 Accepted: 12 August 2019

Published online: 05 September 2019

\section{References}

Alderslade R (1995) Human rights and medical practice, including reference to the joint Oslo statements of September 1993 and March 1994. J Public Health Med 17:335-342

Al-Moujahed A, Alahdab F, Abolaban H, Beletsky L (2017) Polio in Syria: problem still not solved. Avicenna J Med 7:64-66. https://doi.org/10.4103/ajm.AJM_1 73_16

Asgary R (2015) Direct killing of patients in humanitarian situations and armed conflicts: the profession of medicine is losing its meaning. Am J Trop Med Hyg 92:678-680. https://doi.org/10.4269/ajtmh.14-0364

Banatvala N, Zwi AB (2000) Conflict and health. Public health and humanitarian interventions: developing the evidence base. BMJ 321:101-105. https://doi. org/10.1136/bmj.321.7253.101

Baskett PJ (1994) Ethics in disaster medicine. Prehosp Disaster Med 9:4-5 
Ben Shahar I (1993) Disaster preparation and the functioning of a hospital social work department during the Gulf War. Soc Work Health Care 18:147-159. https://doi.org/10.1300/J010v18n03_14

Bernthal EM, Russell RJ, Draper HJ (2014) A qualitative study of the use of the four quadrant approach to assist ethical decision-making during deployment. J R Army Med Corps 160:196-202. https://doi.org/10.1136/jramc-2013-000214

Black R (2003) Ethical codes in humanitarian emergencies: from practice to research? Disasters 27:95-108

Blair L (1996) Medical ethics during genocide. Can Fam Physician 42:1415-1419

Burkle FM Jr et al (2017) The solidarity and health neutrality of physicians in war \& peace. PLoS Curr 9. https://doi.org/10.1371/currents.dis.1a1e352febd595 087cbeb83753d93a4c

Campbell R et al (2011) Evaluating meta-ethnography: systematic analysis and synthesis of qualitative research. Health Technol Assess 15:1-164. https://doi. org/10.3310/hta15430

Chaudhri S, Cordes K, Miller N (2019) Humanitarian health programming and monitoring in inaccessible conflict settings: a literature review. J Int Humanit Action 4. https://doi.org/10.1186/s41018-019-0055-x

Civaner MM, Vatansever K, Pala K (2017) Ethical problems in an era where disasters have become a part of daily life: A qualitative study of healthcare workers in Turkey. PLoS One 12:e0174162. https://doi.org/10.1371/journal. pone.0174162

Clarinval C, Biller-Andorno N (2014) Challenging operations: an ethical framework to assist humanitarian aid workers in their decision-making processes. PLoS Curr 6. https://doi.org/10.1371/currents.dis.96bec99f13 800a8059bb5b5a82028bbf

Cobey JC, Flanagin A, Foege WH (1993) Effective humanitarian aid. Our only hope for intervention in civil war. JAMA 270:632-634. https://doi.org/10.1 001/jama.270.5.632

de Waal A (2010) The humanitarians' tragedy: escapable and inescapable cruelties. Disasters 34(Suppl 2):S130-S137. https://doi.org/10.1111/j.1467-771 7.2010.01149.x

Domres B, Koch M, Manger A, Becker HD (2012) Ethics and triage. Prehosp Disaster Med 16:53-58. https://doi.org/10.1017/s1049023x00025590

Duffield M, Hönke J, Müller M-M (2012) Challenging environments: danger, resilience and the aid industry. Secur Dialogue 43:475-492. https://doi.org/1 $0.1177 / 0967010612457975$

Egeland J, Harmer A, Stoddard A (2011) To stay and deliver: good practice for humanitarians in complex security environments. United Nations Office for the Coordination of Humanitarian Affairs (OCHA)/Policy Development and Studies Branch (PDSB).

Farré S (2013) The ICRC and the detainees in Nazi concentration camps (19421945). Int Rev Red Cross 94:1381-1408. https://doi.org/10.1017/s1816383113 000489

Fegley R (2009) Local needs and agency conflict: a case study of Kajo Keji County, Sudan. Afr Stud Q 11:25-56

Fennell J (1998) Hope suspended: morality, politics and war in central Africa. Disasters 22:96-108

Fink S (2007) Protection of civilians in armed conflict: a decade of promises. In: Cahill KM (ed) The pulse of humanitarian assistance. International Humanitarian Affairs. Fordham University Press and The Center for International Humanitarian Cooperation, New York, pp 22-40

Fouad FM et al (2017) Health workers and the weaponisation of health care in Syria: a preliminary inquiry for The Lancet-American University of Beirut Commission on Syria. Lancet 390:2516-2526. https://doi.org/10.1016/S0140-6 736(17)30741-9

Fraser V, Hunt MR, de Laat S, Schwartz L (2015) The development of a humanitarian health ethics analysis tool. Prehosp Disaster Med 30:412-420. https://doi.org/10.1017/S1049023X1500480X

Gardemann J (2002) Primary health care in complex humanitarian emergencies: Rwanda and Kosovo experiences and their implications for public health training. Croat Med J 43:148-155

Gastineau Campos N, Farmer P (2003) Partners: discernment and humanitarian efforts in settings of violence. J Law Med Ethics 31:506-515

Geiger J, Eisenberg C, Gloyd S, Quiroga J, Schlenker T, Scrimshaw N, Devin J (1989) A new medical mission to El Salvador. N Engl J Med 321:1136-1140. https://doi.org/10.1056/NEJM198910193211629

General Assembly resolution 46/182 (1991) Strengthening of the coordination of humanitarian emergency assistance of the United Nations.

General Assembly resolution 58/114 (2004) Strengthening of the coordination of emergency humanitarian assistance of the United Nations.
Harding-Pink D (2004) Humanitarian medicine: up the garden path and down the slippery slope. BMJ 329:398-399. https://doi.org/10.1136/bmj.329.7462.398

Haver K (2016) Tug of war: ethical decision-making to enable humanitarian access in high-risk environments. Secure Access in Volatile Environments (SAVE), London

Humanitarian Data Exchange (HDX) (2019) SHCC attacks on health care. https:// data.humdata.org/dataset/shcchealthcare-dataset.

Hunt MR (2008) Ethics beyond borders: how health professionals experience ethics in humanitarian assistance and development work. Dev World Bioeth 8:59-69. https://doi.org/10.1111/j.1471-8847.2006.00153.x

Hunt MR (2009) Resources and constraints for addressing ethical issues in medical humanitarian work: experiences of expatriate healthcare professionals. Am J Disaster Med 4:261-271

Hunt MR, Schwartz L, Sinding C, Elit L (2014) The ethics of engaged presence: a framework for health professionals in humanitarian assistance and development work. Dev World Bioeth 14:47-55. https://doi.org/10.1111/dewb.12013

Hurst SA, Mezger N, Mauron A (2009) Allocating resources in humanitarian medicine. Public Health Ethics 2:89-99. https://doi.org/10.1093/phe/phn042

Jaspars S, O'Callaghan S (2010) Livelihoods and protection in situations of protracted conflict. Disasters 34(Suppl 2):S165-S182. https://doi.org/10.1111/ j.1467-7717.2010.01152.x

Jones $L$ (2009) The question of political neutrality when doing psychosocial work with survivors of political violence. Int Rev Psychiatry 10:239-247. https://doi. org/10.1080/09540269874835

Joshi PT, Dalton ME, O'Donnell DA (2008) Ethical issues in local, national, and international disaster psychiatry. Child Adolesc Psychiatr Clin N Am 17:165-185, x-xi. https://doi.org/10.1016/j.chc.2007.07.010

Kass N, Kahn J, Buckland A, Paul A, and the Expert Working Group (2019) Ethics guidance for the public health containment of serious infectious disease outbreaks in low-income settings: lessons from Ebola. https://bioethics.jhu. edu/research-and-outreach/projects/ethics-guidance-lessons-from-ebola/

Labbé J, Daudin P (2016) Applying the humanitarian principles: reflecting on the experience of the International Committee of the Red Cross. Int Rev Red Cross 97:183-210. https://doi.org/10.1017/s1816383115000715

Leaning J, Spiegel P. Crisp J (2011) Public health equity in refugee situations. Confl Health 5:6. https://doi.org/10.1186/1752-1505-5-6

Mačák K (2014) Principles of neutrality and impartiality of humanitarian action in the aftermath of the 2011 Libyan conflict. In: Zwitter A, Lamont CK, Heintze $\mathrm{H}-\mathrm{J}$, Herman J (eds) Humanitarian action: global, regional and domestic legal responses. Cambridge University Press, pp 447-474. https://doi.org/10.1017/ CBO9781107282100.026

MacCormack CF (2007) Coordination and collaboration: an NGO view. In: Cahill KM (ed) The pulse of humanitarian assistance. International Humanitarian Affairs. Fordham University Press and The Center for International Humanitarian Cooperation, New York, pp 243-262

Madhiwalla N, Roy N (2009) Bombing medical facilities: a violation of international humanitarian law. Indian J Med Ethics 6:64-65. https://doi.org/1 0.20529/IJME.2009.023

Michael M, Zwi AB (2002) Oceans of need in the desert: ethical issues identified while researching humanitarian agency response in Afghanistan. Dev World Bioeth 2:109-130

O'Callaghan S, Leach L (2014) The relevance of the fundamental principles to operations: learning from Lebanon. Int Rev Red Cross 95:287-307. https://doi. org/10.1017/s1816383114000228

Omaar R, de Waal A (1994) Humanitarianism unbound? Current dilemmas facing multi-mandate relief operations in political emergencies. African Rights 5

Pictet J (1979) The fundamental principles of the Red Cross. Int Rev Red Cross 19: $130-149$

Poffley R (2012) Holdstock-Piachaud Prize essay. The dilemma of neutrality: to what extent can humanitarian assistance be combined with efforts to promote development? Med Confl Surviv 28:113-123. https://doi.org/10.1 080/13623699.2012.678059

Redwood-Campbell LJ, Sekhar SN, Persaud CR (2014) Health care workers in danger zones: a special report on safety and security in a changing environment. Prehosp Disaster Med 29:503-507. https://doi.org/10.1017/S104 $9023 \times 14000934$

Rieffer-Flanagan BA (2009) Is neutral humanitarianism dead? Red Cross neutrality: walking the tightrope of neutral humanitarianism. Hum Rights Q 31:888-915 https://doi.org/10.1353/hrq.0.0112

Rubenstein LS, Bittle MD (2010) Responsibility for protection of medical workers and facilities in armed conflict. Lancet 375:329-340. https://doi.org/10.1016/ S0140-6736(09)61926-7 
Safeguarding Health in Conflict Coalition (SHCC) (2018) Violence on the front lines: attacks on health care in 2017.

Slim H (1995) The continuing metamorphosis of the humanitarian practitioner: some new colours for an endangered chameleon. Disasters 19:110-126

Slim H (1997a) Doing the right thing: relief agencies, moral dilemmas and responsibility in political emergencies and war. Disasters 21:244-257

Slim H (1997b) Relief agencies and moral standing in war: principles of humanity, neutrality, impartiality and solidarity. Dev Pract 7:342-352

Slim H (2015) Humanitarian ethics: a guide to the morality of aid in war and disaster. Oxford University Press, New York

Sphere Project (2011) Humanitarian charter and minimum standards in humanitarian response. Practical Action Publishing

Sunga LS, Bell DA, Coicaud J-M (2006) Dilemmas facing NGOs in coalitionoccupied Iraq. Ethics in action, pp 99-116. https://doi.org/10.1017/ cbo9780511511233.006

Tribe R, Weerasinghe D, Parameswaran S (2014) Increasing mental health capacity in a post-conflict country through effective professional volunteer partnerships: a series of case studies with government agencies, local NGOs and the diaspora community. Int Rev Psychiatry 26:558-565. https://doi.org/1 0.3109/09540261.2014.918025

Weiss TG (2016) Ethical quandaries in war zones, when mass atrocity prevention fails. Glob Policy 7:135-145. https://doi.org/10.1111/1758-5899.12315

\section{Publisher's Note}

Springer Nature remains neutral with regard to jurisdictional claims in published maps and institutional affiliations.

\section{Submit your manuscript to a SpringerOpen ${ }^{\circ}$ journal and benefit from:}

- Convenient online submission

- Rigorous peer review

- Open access: articles freely available online

- High visibility within the field

- Retaining the copyright to your article

Submit your next manuscript at $\boldsymbol{\nabla}$ springeropen.com 